\title{
Automatisierung passiert nicht automatisch
}

Fertigungsautomation ist seit Langem ein wichtiger Motor der Produktivität. Im Rahmen der sogenannten digitalen Transformation wird sie weiter vorangetrieben. Bei diesem Thema spielen andere viel diskutierte Technologien eine wichtige Rolle. So kommt etwa künstliche Intelligenz (KI) auch in der Fertigungsautomation zum Einsatz. Nicolaos Debowiak - Start-up-Gründer, Geschäftsführer und Experte für Digitalisierung und KI-Technologien weist im Interview mit Wirtschaftsinformatik \& Management darauf hin, dass es in vielen Firmen aber noch am Know-how mangelt, um KI auch in der Automation - effektiv einzusetzen. Er ist sicher, dass es für Unternehmen wichtig ist, dieses Wissen im eigenen Haus zu haben, entsprechende Dienstleistungen einzukaufen, reiche nicht aus.

Ein weiteres wichtiges Schlagwort in diesem Zusammenhang ist Industrie 4.0, das Internet der Dinge. Deutschland ist zwar im internationalen Vergleich bereits recht weit, wenn es um Fertigungsautomation geht, darf sich aber nicht auf seinen Lorbeeren ausruhen - gerade bei Industrie 4.0 drohen uns andere abzuhängen. Insgesamt darf die Rolle des Managements nicht unter den Tisch fallen. Die Weiterentwicklung der Automation muss von der Führungsebene gewollt, unterstützt und begleitet werden, nur dann kann sie erfolgreich sein.

$\mathrm{Zu}$ oft werden Themen wie Fertigungsautomation als rein technische betrachtet. Das sind sie nicht. Automatisierung bietet enorme Chancen - etwa die Möglichkeit, sehr kleine Losgrößen zu produzieren, flexibler auf Kundenwünsche eingehen zu können. Das hat aber auch Folgen, für die Art der Mitarbeiter, die gebraucht werden - Dienstleistung wird dabei an Bedeutung gewinnen, gute Kundenkommunikation ist noch wichtiger. Deutschland ist in einer guten Ausgangsposition, sollte aber nicht verdrängen, dass China gerade in diesem Bereich massiv strategisch handelt - ins Hintertreffen zu geraten, könnte neben wirtschaftlichen auch politische Folgen haben.

Herzliche Grüße

Peter Pagel

Chefredakteur

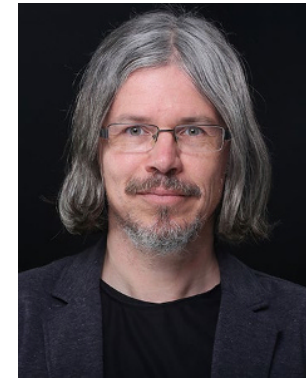

Peter Pagel $(\bowtie)$

peter.pagel@springer.com

Wiesbaden, Deutschland
Wirtschaftsinformatik \& Management 2021 • 13 (5): 339 https://doi.org/10.1365/s35764-021-00361-8

Angenommen: 10. September 2021

Online publiziert: 17. September 2021

(c) Springer Fachmedien Wiesbaden GmbH, ein Teil von Springer Nature 2021 